\title{
PERANAN PENGEMBANGAN PEMAHAMAN BUDAYA KONSUMEN DALAM PROSES INTERNASIONALISASI JASA PENDIDIKAN TINGGI DI INDONESIA
}

\author{
Benedictus Karno Budiprasetyo \\ Universitas Katolik Soegijapranata
}

\begin{abstract}
This empirical research explores how the customer cultural awareness influences the management behavior of the higher education institution and the implementation of the internationalization strategy. Using the data form questionnaire filled by the Indonesian higher education management processed with PLS model estimation, it is found that the customer cultural awareness influence the implementation of the internationalization strategy indirectly through the management behavior. The results shows that the customer cultural awareness significantly influence (OSE:.54 and $\left.R^{2}: .27\right)$ the management behavior and the management behavior significantly influence (OSE:.50 and $R^{2}: .28$ ) the internationalization strategy implementation. This research result was a new phenomenon, since the previous research results shows a direct influence of the customer cultural awareness to the internationalization strategy implementation. The internationalization strategy implementation in the context of customer cultural awareness was depending on the management behavior as a key variable. This research result has its implication that the internationalization process of Indonesian higher education institution in the context of customer cultural awareness should be directed from the management behavior.
\end{abstract}

Keywords : customer cultural awareness, higher education management, resource-based approach.

\section{PENDAHULUAN}

Konsep intercultural competence at the firm level yang dikemukakan oleh Langhoff (1994, dalam Grunert et al., 1996) menyebutkan bahwa perspektif pemahaman budaya merupakan aspek pemerkaya dalam proses spanning (spanning) dan menjadi dasar untuk pembangunan keunggulan bersaing. Kompetensi manajemen dalam pemahaman budaya pelanggan akan menjadi kompetensi yang membedakan perusahaan dengan pesaing, dan hal tersebut akan menjadi faktor penguat dalam pembentukan keunggulan bersaing yang berkesinambungan. Azua dan Azua (1998) secara spesifik menyebutkan perspektif budaya sebagai kohesi sosial (social cohesion), yang digambarkan sebagai kebiasaan, sikap hidup, etika, dan pola hubungan individual dalam organisasi yang dapat menjadi suatu kekayaan (assets) bagi organisasi untuk dipergunakan membangun keunggulan dalam persaingan.

Konsep intercultural competence at the firm level tersebut didasarkan pada pemahaman bahwa kondisi pasar dan kompetisi global yang dinamis akan berimplikasi pada pemahaman lintas budaya yang membutuhkan kemampuan manajemen untuk mengindentifikasi perbedaan budaya global. Kemampuan tersebut akan menjadi dasar untuk menyesuaikan produk atau jasa dengan budaya konsumen maupun pelanggan, dan kemampuan tersebut akan menjadi kunci bagi manajemen untuk mempertahankan pelanggan.

Perbedaan budaya diantara pelanggan tersebut berimplikasi pada penyesuaian produk atau jasa dengan budaya pelanggan (Winsted, 1999), karena budaya masing-masing pelanggan juga menentukan tingkat penerimaan produk atau jasa yang dihasilkan oleh perusahaan (Samiee, 1999). Kebutuhan pemahaman budaya dalam pasar dan kompetisi global tersebut secara 
operasional diterjemahkan sebagai kebutuhan pengembangan pengetahuan dan ketrampilan bahasa, strategic know-how, pengetahuan dan pengalaman menghadapi perbedaan budaya dan regulasi antar negara (O'Farrell et al., 1998).

Sangari dan Foster (1999) melakukan replikasi hasil penelitian Kwok et al. (1995) dengan kasus perbandingan pendidikan internasional di Iran dan Swedia, menemukan fakta bahwa internasionalisasi diantara negara akan berbeda penekanannya, terutama pada aspek budaya. Penelitian tersebut ditegaskan secara teoritik oleh Yang (2002) yang menyatakan bahwa internasionalisasi pendidikan tinggi dapat diartikan sebagai awareness dan interaksi lintas budaya yang menghasilkan pemahaman terhadap adanya perbedaan budaya dalam masyarakat global. Kubow dan Crawford (2001) juga secara teoritik menggagas adanya pemahaman dan penerimaan adanya perbedaan budaya, pemikiran yang kritis, pemahaman atas masalah-masalah global, tanggung jawab terhadap masyarakat, dan perubahan pola hidup yang lebih memperhatikan lingkungan sebagai suatu tuntutan terhadap para sarjana yang dapat diterima secara global.

Pemahaman budaya yang menggunakan pendekatan sumberdaya dalam penelitian Javalgi et al, (2002) secara empirik menunjukkan bahwa pemahaman budaya merupakan variabel yang mempengaruhi internasionalisasi bisnis. Perspektif pemahaman budaya tersebut juga dikemukakan pada beberapa literature review (Howe dan Martin, 1998; Duderstadt, 1999; Lomas, 1999; Gleason et al., 2000; Sherry, 2000; Croxford, 2001; McGee dan Festervand, 2002; Orpen, 2003; Gill dan Lashine, 2003) sebagai variabel yang mempengaruhi strategi pemasaran internasional jasa pendidikan tinggi.

Perspektif pemahaman budaya menurut Gleason et al, (2000), merupakan proses pemahaman internal antar anggota organisasi yang selanjutnya akan membentuk pemahaman dan kemampuan komunikasi lintas budaya dengan pengguna jâsa dan lingkungan eksternal dalam lingkup nasional maupun internasional. Selain pemahaman dan komunikasi lintas budaya individual di atas, secara organisasional juga dibutuhkan pemahaman terhadap elemen social institutions, belief systems, dan material culture, dimana ketiganya mempengaruhi cara pandang organisasi dan individu di dalamnya terhadap lingkungan di luarnya (Gleason et al., 2000). Croxford (2001) menterjemahkan perspektif pemahaman budaya sebagai pemahaman perbedaan budaya dan sensitivitasnya, yang mencakup perbedaan budaya secara individual maupun secara nasional. Pemahaman tersebut dalam lingkungan pendidikan tinggi harus menjadi materi yang diberikan dalam pendidikan tinggi supaya sarjana yang dihasilkannya dapat menjadi sarjana yang dapat bersaing secara global, selain menjadi kemampuan yang harus dimiliki oleh para pengelola pendidikan tinggi.

Pemahaman budaya adalah proses inside-out yang terjadi di dalam organisasi, seperti yang digambarkan dalam Gambar 1. berikut ini.

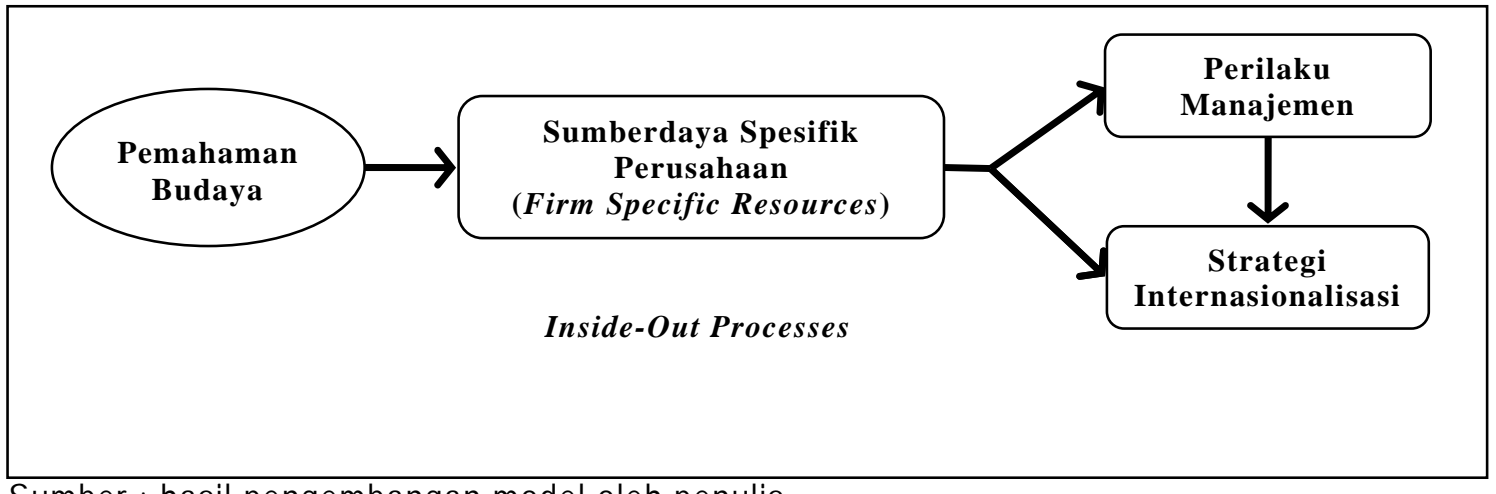

Sumber : hasil pengembangan model oleh penulis

Gambar 1.

Pemahaman Budaya Sebagai Inside-Out Processes dalam Proses Internasionalisasi 
Pada kajian internasionalisasi pendidikan tinggi, banyak sekali pembahasan mengenai aspek budaya, pemahaman budaya antar negara, dan pemahaman budaya konsumen mahasiswa (Bailey, 1995; Sharma dan Roy, 1996; Howe dan Martin, 1998; Lomas, 1999; Gleason et al., 2000; Sherry, 2000; Croxford, 2001; Kubow dan Crawford, 2001; Kwiek, 2001; Moratis dan Baalen, 2002; Javalgi et al., 2002; Yang, 2002; McGee dan Festervand, 2002; Bartell, 2003; Orpen, 2003; Gill dan Lashine, 2003). Namun demikian, belum ada penelitian empirik yang spesifik membahas proses pemahaman budaya dalam kajian internasionalisasi jasa pendidikan tinggi, terutama dengan cakupan penelitian di Indonesia. Khususnya dalam internasionalisasi pendidikan, berbagai dokumen rancangan pengembangan pendidikan tinggi diberbagai negara juga secara integral menyebutkan variabel pemahaman budaya dalam proses internasionalisasi pendidikan tinggi (Gibbons, 1997; UNESCO, 1998; Haug dan Tauch, 1999; MFCED, 2001; EUA, 2003; Wedgwood, 2002; Reichert dan Tauch, 2003; Mosses, 2003; Greer et al., 2004; Wattananimitkul, 2004).

Yang (2002) menyatakan bahwa internasionalisasi pendidikan tinggi dapat diartikan sebagai awareness dan interaksi lintas budaya yang menghasilkan pemahaman terhadap adanya perbedaan budaya dalam masyarakat global. Hal tersebut berimplikasi pada pengembangan knowledge, kemampuan individu, peningkatan value, dan pengembangan berbagai ide yang terkait dengan pemahaman perbedaan budaya dalam masyarakat global. Proses internasionalisasi jasa pendidikan tinggi, menurut Liyanage dan Poon (2003), menuntut adanya pemahaman terhadap kultur, pengembangan knowledge, penggunaan teknologi informasi, perbaikan kualitas, dan pengembangan kerjasama (Kwiek, 2001). Pendidikan tinggi dalam dimensi ekonomi dituntut untuk mampu menciptakan knowledge economy yang menjadi sumber kesejahteraan, menjadi lebih terbuka dalam manajemennya sebagai dimensi politis, menjadi lebih mampu memahami adanya perbedaan budaya dalam masyarakat sebagai dimensi budaya, serta mampu mengintegrasikan informasi dan teknologi komunikasi untuk mengatasi kendala jarak dan waktu sebagai dimensi teknologi. Hal tersebut menurut Bartell (2003) membutuhkan adaptasi organisasional yang ditentukan oleh kepemimpinan yang mampu menginternalisasikan perencanaan strategis untuk mengidentifikasi dan memanfaatkan kekuatan budaya organisasi. Orientasi dan kekuatan budaya dalam sebuah institusi pendidikan tinggi dapat menjadi penghambat maupun sebagai akselerator dalam proses internasionalisasi yang diimplementasi.

Pada kajian pemasaran jasa internasional perspektif pengetahuan dan budaya merupakan dua hal yang tidak terpisahkan (Lindsay, et al., 2003), karena perbedaan kebutuhan jasa pada setiap budaya membuat manajer perlu untuk mengetahuinya (Winstead, 1999), selain perbedaan adaptasi dan penerimaan masing-masing budaya (Samiee, 1999). Kebutuhan pemahaman lintas budaya menjadi kebutuhan untuk pengembangan pengetahuan, yang mencakup ketrampilan bahasa, strategic know-how, pengetahuan dan pengalaman menghadapi perbedaan budaya dan regulasi antar negara (O'Farrell et al., 1998).

Berdasarkan paparan beberapa penelitian empirik dan kajian literatur yang dikemukakan di atas, belum ada penelitian empirik yang secara khusus mengkaji proses pengembangan pemahaman budaya konsumen pengguna jasa pada industri jasa pendidikan tinggi yang mengimplementasikan strategi internasionalisasi. Selain itu, penelitian empirik pada kasus jasa pendidikan tinggi di Indonesia belum pernah ada, sehingga penelitian ini diharapkan akan memberikan gambaran terhadap pola perilaku manajemen dan strategi internasionalisasi dari pendidikan tinggi di Indonesia.

Penelitian ini secara empirik bertujuan untuk menguji pengaruh pemahaman budaya konsumen pengguna jasa pada jasa pendidikan tinggi di Indonesia terhadap perilaku manajemen dari para pengelola institusi pendidikan tinggi di Indonesia dan terhadap strategi internasionalisasi yang diimplementasikan, serta melakukan pengujian secara simultan dari model pengembangan pemahaman budaya konsumen pengguna jasa dalam implementasi strategi internasionalisasi pada jasa pendidikan tinggi di Indonesia. 


\section{KERANGKA KONSEPTUAL DAN PENGEMBANGAN HIPOTESIS}

Konsep intercultural competence at the firm level yang dikemukakan oleh Langhoff (1994) dalam Grunert et al. (1996) sebagai alat analisis untuk mengetahui kemampuan perusahaan untuk mengidentifikasi dan mengeksploitasi peluang pasar dalam konsteks pemahaman budaya merupakan konsep sentral yang menjadi dasar penelitian ini. Konsep tersebut, dalam konteks internasionalisasi jasa pendidikan tinggi didukung oleh banyak literatur (Bailey, 1995; Sharma dan Roy, 1996; Howe dan Martin, 1998; Duderstadt, 1999;Lomas, 1999; Gleason et al., 2000; Sherry, 2000; Croxford, 2001; Kubow dan Crawford, 2001; Kwiek, 2001; Moratis dan Baalen, 2002; Javalgi et al., 2002; Yang, 2002; McGee dan Festervand, 2002; Bartell, 2003; Orpen, 2003; Gill dan Lashine, 2003) dan dokumen rancangan pengembangan pendidikan tinggi diberbagai negara (Gibbons, 1997; UNESCO, 1998; Haug dan Tauch, 1999; MFCED, 2001; EUA, 2003; Wedgwood, 2002; Reichert dan Tauch, 2003; Mosses, 2003; Greer et al., 2004; Wattananimitkul, 2004). Aplikasi konsep tersebut dalam penelitian ini mengandung pengertian penggalian kontribusi pemahaman budaya konsumen pengguna jasa dalam proses internasionalisasi jasa pendidikan tinggi di Indonesia yang dilakukan dengan jalan pembinaan kerjasama dengan institusi pendidikan tinggi asing.

Berdasarkan paparan kajian teoritik dan penelitian empirik yang ada, maka penelitian ini membangun model teoritik dasar yang dipergunakan sebagai landasan pemikiran penelitian. Gambar 2. berikut akan memberikan penjelasan kerangka teoritik yang menjadi landasan penelitian empirik ini.

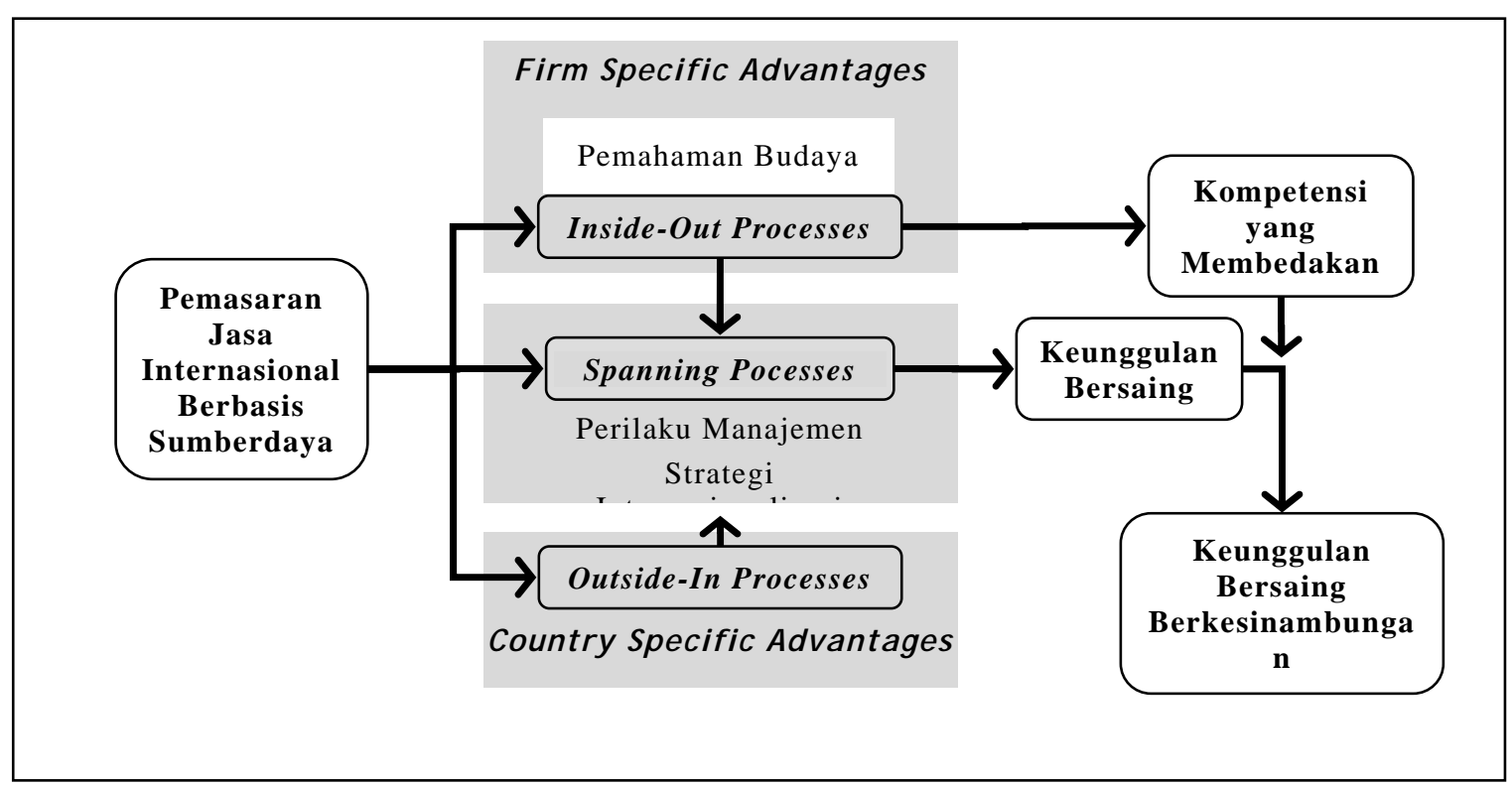

Sumber : hasil pengembangan model oleh penulis

Gambar 2.

Model Teoritik Dasar yang Diusulkan Mengenai Pemahaman Budaya Konsumen Pengguna Jasa Pada Internasionalisasi Pendidikan Tinggi Indonesia

Kerangka teoritik yang menjadi landasan penelitian empirik ini secara empirik diterjemahkan dalam proposisi Gambar 3. Proposisi pengaruh pemahaman budaya sebagai sumberdaya spesifik perusahaan terhadap perilaku manajemen dan strategi internasionalisasi dapat dijelaskan dengan pengertian bahwa pemahaman budaya konsumen pengguna jasa pada institusi pendidikan tinggi dan pola perilaku manajemen dari para pengelola pendidikan tinggi 
Indonesia yang melakukan kerjasama dengan institusi pendidikan tinggi asing memiliki kontribusi terhadap implementasi strategi internasionalisasi yang dilakukan oleh institusi pendidikan tinggi di Indonesia. Berdasarkan pengertian tersebut, maka secara empirik pola keterkaitan antar variabel tersebut dapat dibangun menjadi model pemahaman budaya dalam kerangka internasionalisasi pendidikan tinggi di Indonesia.

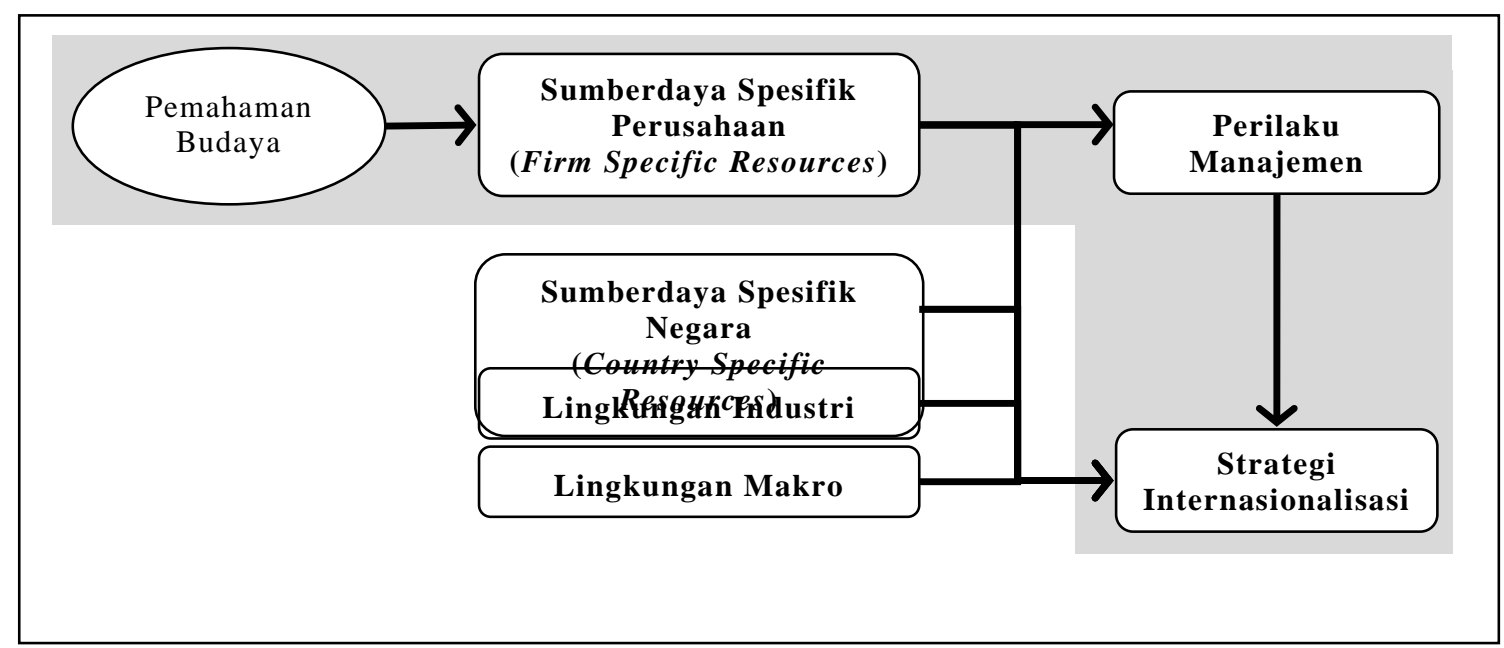

Sumber : hasil pengembangan model oleh penulis

\section{Gambar 3.}

Proposisi Pengaruh Pemahaman Budaya Sebagai Sumberdaya Spesifik Perusahaan terhadap Perilaku Manajemen dan Strategi Internasionalisasi

Berdasarkan kerangka teoritik dan bangunan proposisi yang dibangun dalam penelitian ini, selanjutnya dibangun model empirik (Gambar 4.) yang menjadi dasar dalam pengembangan dan pengujian hipotesis penelitian. Pada Gambar 4. menjelaskan bahwa variabel pemahaman budaya diukur dengan 4 (empat) indikator, yaitu ; pemahaman lintas budaya internasional, pemahaman budaya pengguna jasa (Mazzarol, 1998), kebijakan pemahaman lintas budaya, dan implementasi kebijakan pemahaman lintas budaya (Lomas, 1999). Variabel perilaku manajemen di ukur dengan 5 (lima) indikator, yaitu ; orientasi tugas (Javalgi et al., 2003; Winsted dan Patterson, 1998), kemampuan penyelenggaraan (Javalgi et al., 2003), orientasi kompetisi, keberlangsungan institusi, dan kesejahteraan institusi (Winsted dan Patterson, 1998). Sedangkan variabel strategi internasionalisasi diukur dengan 9 (sembilan) indikator, yaitu ; mahasiswa internasional (Javalgi et al., 2000; Mazzarol, 1998), internasionalisasi kurikulum (Howe dan Martin, 1998; Kwok et al., 1995; Raimond dan Halliburton, 1995; Sangari dan Foster, 1999), bahasa internasional (Yang, 2002; Bailey, 1995), kerjasama universitas asing (Javalgi et al., 2000), pertukaran staf (Svensson, 1994; Bailey, 1995; Sharma dan Roy, 1996; Welch, 1997; Welch dan Denman, 1997), kerjasama penelitian (Kwok et al., 1995; Bailey, 1995; Yang, 2002), kerjasama industri internasional (Drilhon, 1993; Bailey, 1995), pertukaran mahasiswa (Yang, 2002; Bailey, 1995), dan implementasi internasionalisasi secara langsung (Bell, 1995; Okoroafo, 1991; Rundh, 1994; 2003; Robertson dan Chetty, 2000). 


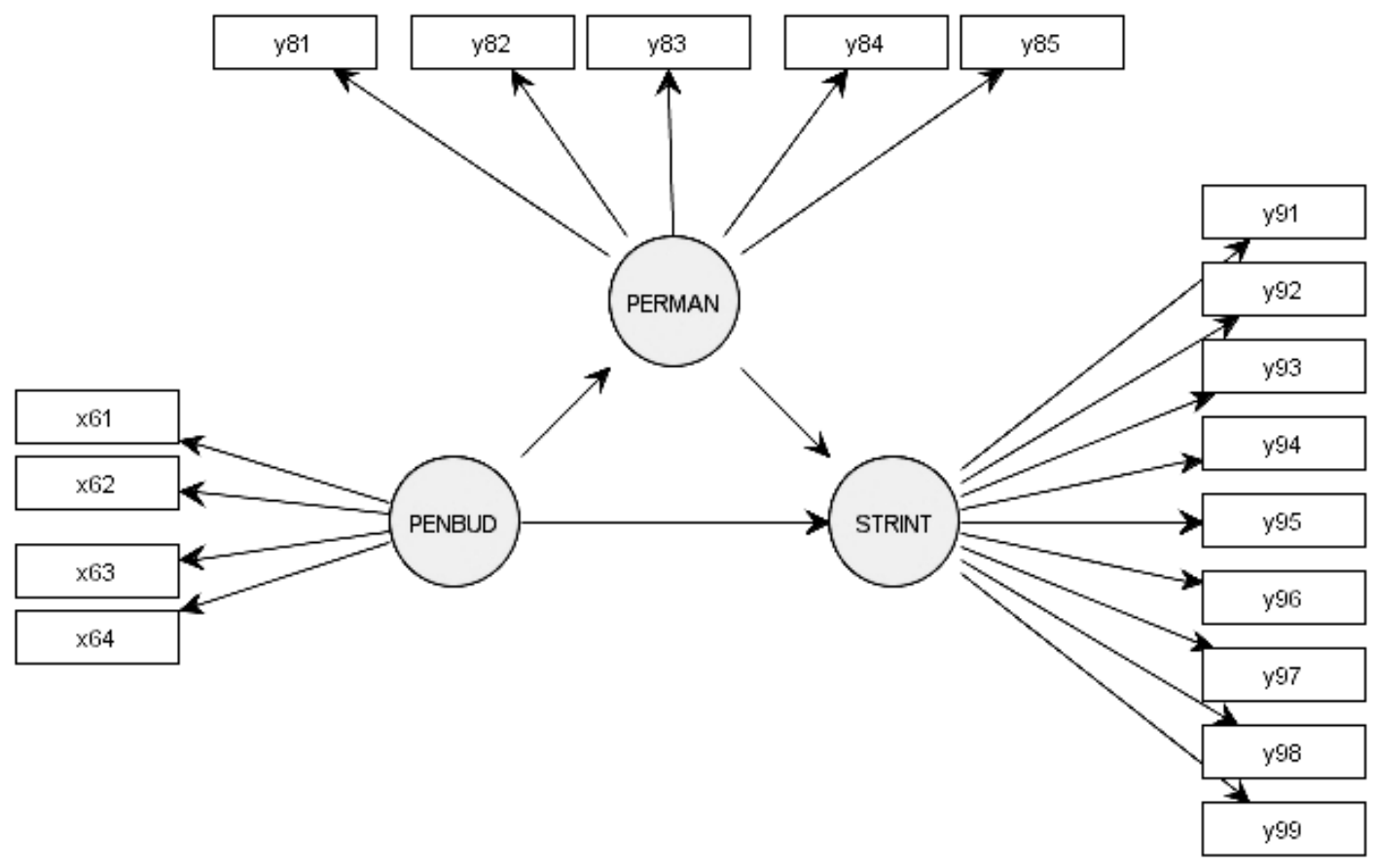

Gambar 4.

Model Empirik Pengaruh Pengembangan Manajemen Pengetahuan Terhadap Strategi Internasionalisasi

Berdasarkan dukungan pemahaman teoritik dan penelitian empirik terdahulu, serta tujuan penelitian untuk memperjelas keterkaitan manajemen pengetahuan sebagai bagian dari proses inside-out yang mempengaruhi proses spanning (perilaku manajemen dan strategi internasionalisasi), maka dirumuskan beberapa hipotesis sebagai berikut :

Hipotesis 1. Pola pengembangan pemahaman budaya konsumen pengguna jasa pada institusi pendidikan tinggi di Indonesia yang menjalin kerjasama dengan institusi pendidikan tinggi asing berpengaruh positif terhadap pola perilaku manajemen para pengelola institusi pendidikan tinggi di Indonesia.

Hipotesis 2. Pola pengembangan pemahaman budaya konsumen pengguna jasa pada institusi pendidikan tinggi di Indonesia yang menjalin kerjasama dengan institusi pendidikan tinggi asing berpengaruh positif terhadap implementasi strategi internasionalisasi pada institusi pendidikan tinggi di Indonesia.

Hipotesis 3. Pola perilaku manajemen para pengelola institusi pendidikan tinggi Indonesia yang menjalin kerjasama dengan institusi pendidikan tinggi asing berpengaruh positif terhadap implementasi strategi internasionalisasi pada institusi pendidikan tinggi di Indonesia.

Pengembangan hipotesis penelitian ini didasarkan pada tujuan penelitian ini, yaitu untuk mengetahui apakah pengembangan pemahaman budaya konsumen pengguna jasa yang dilakukan mempengaruhi perilaku manajemen dan strategi internasionalisasi dari institusi pendidikan tinggi Indonesia yang bekerjasama dengan pendidikan tinggi asing. Hasil pengujian hipotesis tersebut akan memberikan penjelasan empirik keterkaitan dan peranan pemahaman budaya konsumen pengguna jasa dalam proses internasionalisasi institusi pendidikan tinggi di Indonesia. 


\section{METODA PENELITIAN}

Penelitian ini dirancang untuk menguji model hubungan multiple relationships antar variabel, yang melibatkan banyak variabel dan informasi yang ingin diperoleh bersifat simultan (Hair et al., 1998; Ferdinand, 2002), sehingga secara kuantitatif teknik analisis yang digunakan adalah Partial Least Square model estimation dengan mempergunakan software SMART Partial Least Square. PLS model estimation adalah teknik structural equation modelling (SEM) berbasis varian, untuk mengestimasi jalur hubungan antara variabel laten yang dibentuk oleh beberapa indikator. PLS model estimation sering disebut sebagai soft modelling (Falk dan Miller, 1992; O'Cass dan Julian, 2003) yang tidak membutuhkan asumsi normalitas secara multivariat (Kroonenberg, 1990). Secara teknis, analisis data dan output perhitungan PLS model estimation terdiri dari model pengukuran (measurement/outer model) yang mengukur hubungan variabel laten dan indikatornya, dan model struktural (structural inner model) yang mengukur hubungan antar variabel laten dan diinterpretasikan dari koefisien regresi yang dihasilkan (Falk dan Miller, 1992; Kroonenberg, 1990; O'Cass dan Julian, 2003; Sun dan Zhang, 2004).

\subsection{Profil Responden}

Pada Tabel 1. menggambarkan bahwa mayoritas responden dalam penelitian ini cenderung setuju dan sangat setuju terhadap keempat indikator dalam pengukuran variabel pemahaman budaya.

Tabel 1.

Deskripsi Jawaban Responden Terhadap Variabel Pemahaman Budaya

\begin{tabular}{lrrrrr}
\hline \multicolumn{1}{c}{ Pemahaman Budaya } & STS & TS & RR & S & SS \\
\hline Upaya pemahaman perbedaan budaya dalam lingkup & 0 & 2 & 2 & 23 & 28 \\
internasional & 0 & 1 & 4 & 30 & 20 \\
Upaya pemahaman perbedaan budaya para pengguna jasa & 0 & 5 & 9 & 28 & 13 \\
Pembentukan kebijakan pemahaman perbedaan budaya & 0 & 6 & 9 & 31 & 9 \\
Implementasi kebijakan pemahaman perbedaan budaya & 0
\end{tabular}

Sumber : data primer yang diolah

Namun demikian, masih ada responden yang tidak setuju atau ragu-ragu terhadap pengukuran pemahaman budaya tersebut. Terutama yang berkaitan dengan upaya pembentukan kebijakan pemahaman budaya maupun implementasinya. Hal tersebut menunjukkan bahwa upaya pemahaman budaya tidak harus menjadi variabel yang harus dituangkan dalam bentuk kebijakan tertulis, karena penterjemahannya dalam bentuk kebijakan relatif sulit. Selain itu, masih terdapat responden yang tidak setuju ataupun ragu-ragu terhadap indikator upaya pemahaman perbedaan budaya dalam lingkup internasional dan para pengguna jasa, yang menunjukkan bahwa terdapat implementasi strategi internasionalisasi yang tidak menerapkan upaya pemahaman perbedaan budaya internasional maupun budaya konsumen pengguna jasa pendidikan tinggi. 
Tabel 2.

Deskripsi Jawaban Responden Terhadap Variabel Perilaku Manajemen

\begin{tabular}{lrrrrr}
\hline \multicolumn{1}{c}{ Perilaku Manajemen } & STS & TS & RR & S & SS \\
\hline Sudah tugas pengelola yang harus diimplementasikan & 0 & 0 & 1 & 20 & 34 \\
$\begin{array}{l}\text { Perhitungan kemampuan penyelenggaraan kerjasama } \\
\text { internasional }\end{array}$ & 0 & 0 & 4 & 29 & 22 \\
$\begin{array}{l}\text { Orientasi untuk berkompetisi di lingkungan lokal dan } \\
\text { internasional }\end{array}$ & 0 & 0 & 1 & 27 & 27 \\
Upaya mempertahankan keberlangsungan institusi & 0 & 1 & 4 & 17 & 33 \\
Upaya untuk meningkatkan kesejahteraan institusi dan & 0 & 2 & 7 & 28 & 18 \\
anggotanya & & & & &
\end{tabular}

Sumber : data primer yang diolah

Pada Tabel 2. digambarkan bahwa mayoritas responden dalam penelitian ini cenderung setuju dan sangat setuju terhadap seluruh indikator dalam pengukuran variabel perilaku manajemen. Internasionalisasi pendidikan tinggi dianggap oleh para pengelola pendidikan tinggi sebagai sebuah tugas yang harus diimplementasikan, dan merupakan salah satu upaya untuk mempertahankan keberlangsungan institusi yang dikelolanya. Tingkat persetujuan responden terhadap kedua indikator di atas masih lebih tinggi dibandingkan tanggapan responden terhadap kemampuan institusi untuk menyelenggarakan kerjasama internasional dan upaya untuk meningkatkan kesejahteraan anggota institusi. Walaupun tingkat persetujuan responden dalam penelitian ini sangat tinggi, masih ada reponden yang menyatakan ketidak setujuan dan keraguan. Artinya, terdapat pengelola pendidikan tinggi di Indonesia yang ragu-ragu bahwa internasionalisasi pendidikan tinggi yang dilakukan didasarkan pada perhitungan kemampuan institusi selain juga merupakan upaya untúk mempertahankan keberlangsungan institusi dan meningkatkan kesejahteraan institusi dan anggotanya.

Tabel 3.

Deskripsi Jawaban Responden Terhadap Variabel Strategi Internasionalisasi

\begin{tabular}{lrrrrr}
\hline \multicolumn{1}{c}{ Strategi Internasionalisasi } & STS & TS & RR & S & SS \\
\hline Adanya mahasiswa internasional dari luar negeri & 5 & 16 & 8 & 18 & 8 \\
Internasionalisasi muatan kurikulum & 1 & 4 & 7 & 19 & 24 \\
Penggunaan bahasa internasional & 0 & 3 & 2 & 28 & 22 \\
Kerjasama dengan universitas asing & 1 & 10 & 7 & 19 & 18 \\
Pertukaran staf pengajar & 0 & 6 & 5 & 26 & 18 \\
Program kerjasama penelitian dalam lingkup internasional & 1 & 7 & 4 & 28 & 15 \\
Kerjasama institusi dengan dunia industri internasional & 1 & 8 & 9 & 26 & 11 \\
Pertukaran mahasiswa internasional & 3 & 7 & 3 & 33 & 9 \\
Langsung, tanpa harus melakukannya secara bertahap & 5 & 20 & 9 & 15 & 6 \\
\hline
\end{tabular}

Sumber : data primer yang diolah

Pada Tabel 3. digambarkan bahwa terdapat perimbangan pendapat antara setuju dan tidak setuju, menurut responden para pengelola pendidikan tinggi Indonesia yang menjalin kerjasama dengan institusi asing, dimana internasionalisasi pendidikan tinggi berkaitan dengan adanya mahasiswa internasional maupun memiliki kerjasama dengan universitas asing. Justru yang paling penting dalam kerangka internasionalisasi tersebut adalah memberikan muatan internasional dalam kurikulum pendidikan yang diberikan kepada mahasiswa. Selain itu juga penggunaan bahasa internasional, kerjasama penelitian maupun dengan industri dalam lingkup internasional, pertukaran staf pengajar maupun pertukaran mahasiswa internasional. Tabel 3. 
tersebut di atas juga menggambarkan bahwa internasionalisasi pendidikan tinggi yang diimplementasikan bisa dilakukan secara bertahap maupun secara langsung, tanpa harus menunggu waktu yang relatif lama. Hal tersebut dikonfirmasikan dengan kenyataan bahwa implementasi kerjasama yang dijalin dengan institusi pendidikan tinggi asing dilakukan baik oleh institusi pendidikan tinggi Indonesia yang berumur lebih dari 25 tahun, maupun yang baru didirikan kurang dari 10 tahun. Perilaku implementasi kerjasama internasional tersebut merupakan fenomena yang menarik karena pola perilaku manajemen dari institusi pendidikan tinggi Indonesia yang relatif muda lebih berani untuk memasuki tahapan dan target pasar secara internasional.

\section{PEMBAHASAN HASIL PENELITIAN}

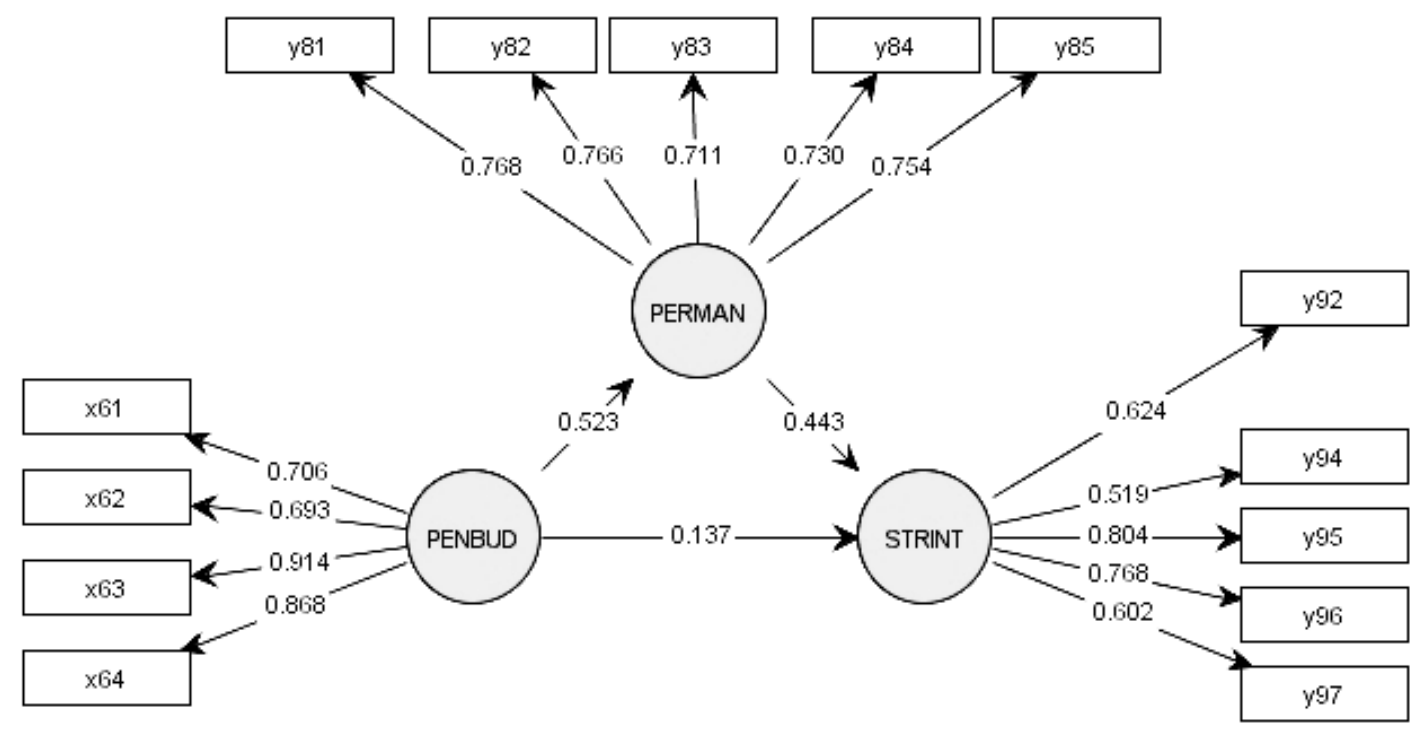

Gambar 5.

Hasil Akhir PLS Model Estimation Pada Model Empirik yang diuji

Pada Gambar 5. terlihat bahwa terdapat 4 (empat) indikator dari variabel strategi internasionalisasi yang tidak signifikan dalam membentuk variabel strategi internasionalisasi. Keempat indikator tersebut adalah: adanya mahasiswa internasional dari luar negeri, penggunaan bahasa internasional, pertukaran mahasiswa internasional, dan implementasi strategi internasionalisasi secara langsung. 
Tabel 4.

Signifikansi Indikator Pembentuk Variabel Laten Pada Model Empirik

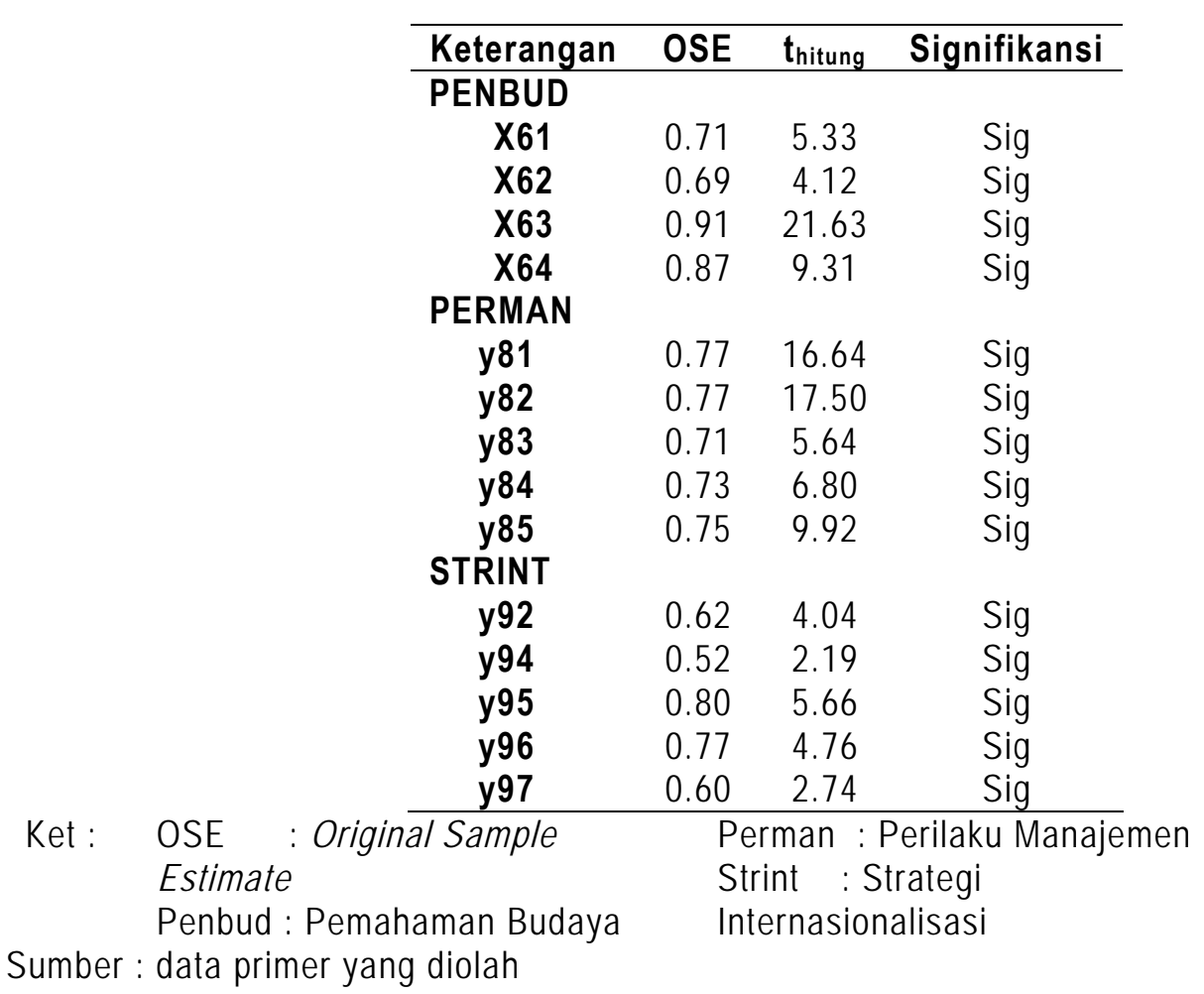

Berdasarkan perhitungan convergent validity dari model pengukuran yang dicerminkan dari nilai original sample estimate dan nilai thitung dari masing-masing indikator pada Tabel 4., disimpulkan bahwa model empirik yang ditunjukkan dalam Gambar 5. di atas merupakan model empirik yang disusun dengan indikator yang valid dan signifikan dalam membentuk masing-masing variabel latennya.

Tabel 5. berikut ini menunjukkan bahwa nilai akar AVE untuk seluruh variabel laten yang dipergunakan dalam penelitian ini lebih besar dibandingkan nilai korelasi variabel satu dengan variabel lainnya. Hal tersebut menunjukkan bahwa indikator masing-masing variabel laten mampu menjelaskan pengertian variabel laten yang dibentuk dalam penelitian ini. Berdasarkan perhitungan cross loading dan perbandingan nilai akar AVE dengan korelasi variabel laten yang pada Tabel 5. menunjukkan bahwa seluruh indikator memiliki kemampuan untuk menjelaskan pengertian variabel laten yang dibentuknya.

Tabel 5.

Nilai Average variance extracted (AVE) Korelasi Antar Variabel Laten, dan Nilai Composite Reliability Pada Model Empirik

\begin{tabular}{lcccccc}
\hline Keterangan & AVE & $\begin{array}{c}\text { Akar } \\
\text { AVE }\end{array}$ & $\begin{array}{c}\text { Korelasi } \\
\text { Manpen }\end{array}$ & Perman & Strint & $\begin{array}{c}\text { Composite } \\
\text { Reliability }\end{array}$ \\
\hline MANPEN & 0.64 & 0.80 & 1.00 & & & 0.88 \\
PERMAN & 0.56 & 0.75 & 0.52 & 1.00 & & 0.86 \\
STRINT & 0.45 & 0.67 & 0.37 & 0.52 & 1.00 & 0.80 \\
\hline
\end{tabular}

Ket : AVE : Average Variance Extracted

Sumber : data primer yang diolah 
Batasan penerimaan nilai reliabilitas komposit adalah sebesar 0,60 , sehingga hasil perhitungan reliabilitas komposit pada Tabel 5. menunjukkan penerimaan reliabilitas blok indikator reflektif yang membentuk variabel latennya karena nilai reliabilitas komposit seluruh variabel yang ada lebih besar dari nilai batas penerimaan reliabilitas.

Tabel 6.

Nilai $R$-square Pada Model Empirik

\begin{tabular}{lcccc}
\hline \multicolumn{1}{c}{ Keterangan } & OSE & thitung $_{\text {he }}$ & Signifikansi & $\begin{array}{c}\boldsymbol{R} \text { - } \\
\text { square }\end{array}$ \\
\hline PENBUD $\Rightarrow$ PERMAN & 0.52 & 5.47 & Sig & 0.27 \\
PERMAN $\Rightarrow$ STRINT & 0.44 & 3.25 & Sig & 0.28 \\
PENBUD $\Rightarrow$ STRINT & 0.14 & 0.79 & T.Sig & 0,28 \\
\hline
\end{tabular}

Sumber : data primer yang diolah

Tabel 6. menunjukkan bahwa variabel manajemen pengetahuan mempengaruhi perubahan variabel perilaku manajemen sebesar 29 persen dan bahwa variabel perilaku manajemen mempengaruhi perubahan variabel strategi internasionalisasi sebesar 28 persen. Nilai $R$-square tersebut mencerminkan kekuatan prediksi dari keseluruhan model (Falk dan Miller, 1992) dengan batasan nilai $R$-square lebih besar dari 0,10 atau lebih besar dari 10 persen.

Tabel 6. tersebut juga memperlihatkan bahwa pemahaman budaya konsumen pengguna jasa di dalam institusi pendidikan tinggi Indonesia yang bekerjasama dengan institusi pendidikan tinggi asing di estimasikan mempengaruhi pola perilaku manajemen sebesar 0,54 dan selanjutnya pola perilaku manajemen tersebut mempengaruhi implementasi strategi internasionalisasi sebesar 0,50 seperti yang digambarkan sebagai rute stratejik pengembangan manajemen pengetahuan dalam proses internasionalisasi pendidikan tinggi di Indonesia dalam Gambar 6. berikut ini.

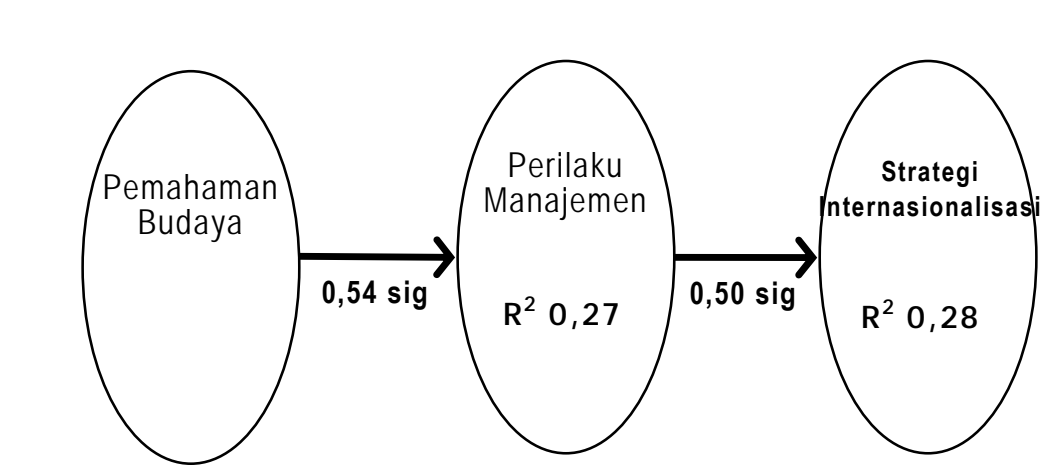

Keterangan : Sig $=$ Signifikan pada $\alpha=5 \%$

$(1,960)$

Gambar 6.

Rute Stratejik Pada Model Empirik yang diuji

Berdasarkan hasil PLS-model estimation yang dievaluasi dari model pengukuran dan model struktural dalam rangkaian perhitungan di atas, maka ketiga hipotesis yang dibangun dalam penelitian empirik ini hanya dapat membuktikan dua hipotesis saja. Hipotesis pertama yang menyatakan bahwa pemahaman budaya konsumen pengguna jasa pada institusi pendidikan tinggi di Indonesia yang menjalin kerjasama dengan institusi pendidikan tinggi asing berpengaruh positif terhadap pola perilaku manajemen para pengelola institusi pendidikan tinggi di Indonesia terbukti 
berpengaruh positif dan signifikan. Hipotesis ketiga yang menyatakan bahwa pola perilaku manajemen para pengelola institusi pendidikan tinggi Indonesia yang menjalin kerjasama dengan institusi pendidikan tinggi asing berpengaruh positif terhadap implementasi strategi internasionalisasi pada institusi pendidikan tinggi di Indonesia juga terbukti berpengaruh positif dan signifikan. Sedangkan hipotesis kedua yang menyatakan bahwa pemahaman budaya konsumen pengguna jasa pada institusi pendidikan tinggi di Indonesia yang menjalin kerjasama dengan institusi pendidikan tinggi asing berpengaruh positif terhadap implementasi strategi internasionalisasi pada institusi pendidikan tinggi di Indonesia ternyata tidak terbukti berpengaruh signifikan.

Hasil pengujian ketiga hipotesis tersebut menunjukkan bahwa pemahaman budaya konsumen pengguna jasa pada institusi pendidikan tinggi Indonesia yang melakukan kerjasama dengan institusi pendidikan tinggi asing memberikan kontribusi secara tidak langsung terhadap implementasi strategi internasionalisasi melalui pola perilaku manajemen dari para pengelola institusi pendidikan tinggi tersebut. Artinya, perilaku manajemen para pengelola institusi pendidikan tinggi Indonesia tersebut merupakan variabel kunci dalam proses implementasi strategi internasionalisasi yang dilakukan selama ini.

Temuan penelitian ini tidak sepenuhnya bertentangan dengan hasil penelitian yang dilakukan oleh sejumlah peneliti (Sharma et al., 1995; Mazzarol, 1998; O'Farrell et al., 1998; Winsted, 1999; Samiee, 1999) dan konsep internasionalisasi pendidikan tinggi dalam konteks pemahaman budaya yang dikemukakan dalam banyak dokumen internasionalisasi pendidikan tinggi (Gibbons, 1997; UNESCO, 1998; Haug dan Tauch, 1999; MFCED, 2001; EUA, 2003; Wedgwood, 2002; Reichert dan Tauch, 2003; Mosses, 2003; Greer et al., 2004; Wattananimitkul, 2004). Temuan penelitian ini justru memperkaya pemahaman konsep internasionalisasi pendidikan tinggi yang banyak dikemukakan bahwa proses pemahaman budaya yang dikembangkan oleh para pengelola pendidikan tinggi di Indonesia tidak dapat dilepaskan dari peran perilaku manajemen para pengelola pendidikan tinggi.

Sedangkan hasil penelitian ini mendukung hasil penelitian yang dilakukan oleh Javalgi et al., (2002) serta Connelly dan Kelloway (2003), yang menyatakan bahwa pemahaman budaya berpengaruh terhadap perilaku manajemen. Artinya, penelitian ini menyempurnakan konsep dan hasil penelitian empirik sebelumnya dengan temuan yang menyatakan bahwa proses pengembangan pemahaman budaya yang dilakukan oleh institusi pendidikan tinggi di Indonesia berpengaruh secara tidak langsung terhadap implementasi strategi internasionalisasi melalui perilaku manajemen dari para pengelola pendidikan tinggi.

Konsekuensi dari temuan penelitian ini adalah adanya peran perilaku manajemen sebagai variabel yang menjembatani keterkaitan antara proses pengembangan pemahaman budaya konsumen pengguna jasa yang dilakukan oleh manajemen institusi dalam implementasi strategi internasionalisasi yang dilakukan oleh institusi. Peran perilaku manajemen sebagai variabel jembatan inilah yang tidak ditemukan dalam penelitian empirik dan pengembangan konsep model manajemen pemasaran jasa internasional berbasis sumberdaya sebelumnya, sehingga model manajemen pemasaran jasa internasional berbasis sumberdaya yang dikembangkan dalam penelitian ini memberikan kontribusi pengembangan model teoritik yang lebih sempurna. Selain itu, temuan dalam penelitian ini juga memperjelas konsep hubungan antara proses inside-out terhadap proses spanning yang diproporsikan dalam penelitian ini.

\section{PENUTUP}

Variabel pemahaman budaya yang mewakili proses identifikasi kekuatan spesifik dari institusi (inside-out processes) secara empirik berpengaruh terhadap pola perilaku manajemen sebagai bagian dari proses penjalinan (spanning processes) dan berpengaruh secara tidak langsung terhadap strategi internasionalisasi. Fenomena baru yang ditemui dalam penelitian ini menyatakan bahwa terdapat pengaruh positif dan signifikan antara variabel pemahaman budaya 
sebagai proses inside-out secara tidak langsung terhadap pola pengembangan strategi internasionalisasi institusi pendidikan tinggi di Indonesia melalui perilaku manajemen. Artinya, perilaku manajemen para pengelola institusi pendidikan tinggi di Indonesia merupakan variabel kunci yang menjembatani kontribusi pemahaman budaya konsumen pengguna jasa dalam proses implementasi strategi internasionalisasi.

Sejalan dengan hasil penelitian empirik ini, maka dibutuhkan penelitian lanjutan yang secara spesifik mengindentifikasi tingkatan pemahaman budaya konsumen pengguna jasa yang berkaitan dengan pola perilaku manajemen dan implementasi strategi internasionalisasi, agar dapat memberikan batasan-batasan tertentu dalam implementasi strategi internasionalisasi.

\section{DAFTAR PUSTAKA}

Azua, J., and Azua, S. (1998) "Corporation Strategies for Defining Competitive Industrial Policies, Arthur Andersen \& KPMG", Paper presented in Strategic Management Society Conference, Orlando

Bailey, E.K. (1995), "An Academic Model of Excellence for International Business Education", Journal of Management Development, Vol. 14 No. 5, pp. 50-60.

Bartell, M. (2003), "Internationalization of Universities: A University Culture-Based Framework", Higher Education 45: 43-70.

Bell, J. (1995), "The Internationalization of Small Computer Software Firms: A Further Challenge to Stage Theories", European Journal of Marketing, Vol. 29 No. 8, pp. 60-75.

Connely, C.E., and Kelloway, E.K. (2003), "Predictors of Employees Perceptions of Knowledge Management Sharing Cultures", Leadership and organization development journal, 24/5 [2003] 294-301

Croxford, L. (2001), "Global University Education: Some Cultural Considerations", Higher Education in Europe, Vol. XXVI, No. 1. 53-60

Drilhon, G. (1993), "University-Industry Relations, Regionalisation, Internationalisation", Higher Education Management, 5(1), pp. 95-99.

Duderstadt, J.J. (1999), "The Future of Higher Education New Roles for the 21st-Century University," Issues in Science and Technology Online, Winter. , didownload Maret, 2004

EUA (2003), "Forward from Berlin: The Role of Universities to 2010 and Beyond," European University Association, Leuven, 4 July 2003, didownload Maret, 2004

Falk, R.F. and Miller, N.B. (1992), A Primer for Soft Modeling, University of Akron Press, Akron, $\mathrm{OH}$.

Ferdinand, A. (2002), Structural Equation Modelling dalam Penelitian Manajemen, BP Undip, Semarang.

Gibbons, M. (1997), "What Kind of University? Research and Teaching in The 21st Century, Beanland Lecture," Victoria University of Technology, didownload Maret, 2004 
Gill, A., and Lashine, S. (2003), "Business Education: A Strategic Market-Oriented Focus," The International Journal of Educational Management, 17/5; 188-194

Gleason, K.C., Mathur, L.K, and Mathur, I. (2000), "The Interrelationship Between Culture, Capital Structure, and Performance: Evidence from European Retailers," Journal of Business Research 50, 185-191.

Greer, L., Robinson, T., and Sweetman, T. (2004), Approaches to Learning: An International Comparison of H igher Education in The Former Socialist States of Central and Eastern Europe, Teesside Business School, University of Teesside, Middlesbrough, didownload Maret, 2004

Grunert, K.G., Baadsgaard, A., Larsen, H.H., and Madsen, T.K. (1996), Market Orientation in Food and Agriculture, Kluwer Academics Publishers, Boston, MA.

Hair, J., Anderson, R.E., Tatham, R.L., and Black, W.C. (1998), Multivariate Data Analysis, Prentice Hall Internasional. Inc, New Jersey.

Haug, G. and Tauch, C. (2004), "Towards The European Higher Education Area : Survey of Main Reforms from Bologna to Prague," didownload Maret, 2004

Howe, WS. and Martin, G. (1998), "Internationalisation Strategies for Management Education," Journal of Management Development, Vol. 17 No. 6. 447-462.

Javalgi, R.G., Nance, J.J., and White, D.S. (2002), "Strategic Challenges for The Marketing of Services Internationally," International Marketing Review, Vol. 19 No. 6, pp. 563-581.

Javalgi, R.G., Nance, J.J., Griffith, D.A., and White, D.S. (2003), "An Empirical Examination of Factors Influencing The Internationalization of Service Firms," Journal of Services Marketing, 17/2. 185-201.

Javalgi, R.G., White, D.S., and Lee, O. (2000), "Firm Characteristics Influencing Export Propensity: An Empirical Investigation by Industry Type," Journal of Business Research 47, 217-228.

Kroonenberg, P.M. (1990), "Review of Latent Variable Modelling with Partial Least Squares by Jan-Bernd Lohmoller," Journal of the American Statistical Association, September, pp. 909-10.

Kubow, P.K., and Crawford, S.H. (2001), "Building Global Learning Experiences: A Case Study of a Hungarian, Ukrainian, and American Educational Partnership," Higher Education in Europe, Vol. XXVI, No. 1. 77-85.

Kwiek, M. (2001), "Globalization and Higher Education," Higher Education in Europe, Vol. XXVI, No. 1, 27-38.

Kwok, C.Y., Arpan, J. and Folks, Jr, W.R. (1995), "A Global Survey of International Business Education in The 1990s'," Journal of International Business Studies, Vol. 25 No. 3, pp. 605-23.

Lindsay, V., Chadee, D., Mattson, J., Johnston, R., and Millett, B. (2003), "Relationships, The Role of Individuals and Knowledge Flows in The Internasionalisasi of Service Firms," Internasional Journal of Service Industry Management, Vol. 14 No. 1, pp. 7-35 
Liyanage, S., and Poon, P.S. (2003), "Technology and Innovation Management Learning in The Knowledge Economy A Techno-Managerial Approach," Journal of Management Development, Vol. 22 No. 7. 579-602.

Lomas, L. (1999), "The Culture and Quality of Higher Education Institutions: Examining The Links," Quality Assurance in Education, Volume 7 · Number 1, 30-34.

Mazzarol, T. (1998), "Critical Success Factors for International Education Marketing," International Journal of Educational Management 12/4.163-175.

McGee, J.E., and Festervand, T.A. (2002), "Delivering a Graduate Course in Cross-Cultural Management in Portugal: Observations, Experiences, and Academic Axioms," Cross Cultural Management, Volume 9 Number 1, 56-71.

MFCED (2001), 'Education in Flanders : The Flemish Educational Landscape in A Nutshell," Ministry of the Flemish Community Education Department, didownload Maret, 2004

Moratis, L.T., and Baalen P.J. (2002), "The Radicalization of The Multiversity: The Case of The Networked Business School," The International Journal of Educational Management, 16/4, 160-168.

Moses, Y.T. (2003), "Diversity and The New American University," Fourth Annual Faculty Development Conference Arizona State University, October 30, didownload Maret, 2004.

O'Farrell, P.N., Wood, P.A. and Zheng, J. (1998), "Regional Influences on Foreign Market Development by Business Service Companies: Elements of A Strategic Context Explanation," Regional Studies, Vol. 2 No. 10, pp. 31-48.

Okoroafo, S.C. (1991), "Modes of entering foreign markets," Industrial Market Management, Vol. 20 No. 4, pp. 341-6.

Orpen, C. (2003), "Teaching Students to Manage Cross Culturally," Cross Cultural Management, Volume 10 Number 3, 80-86.

Raimond, P., and Halliburton, C. (1995), "Business School Strategies for The Single European Market," Management Learning, Vol. 26 No. 2, pp. 231-48.

Reichert, S., and Tauch, C. (2003), "Trends 2003 Progress Towards The European Higher Education Area : Bologna Four Years After: Steps Toward Sustainable Reform of Higher Education in Europe," The European University Association.

Robertson, C. and Chetty, S.K. (2000), "A Contingency-Based Approach to Understanding Export Performance," International Business Review, No. 9, pp. 211-35.

Rundh, B. (1994), "The Process of Internationalisation : A Study of The Swedish Manufacturing Industry," Research Report, No. 94, p. 13, Department of Business Administration and Economics, University of Karlstad, Karlstad.

Rundh, B. (2003), "Rethinking The International Marketing Strategy: New Dimensions in A Competitive Market," Marketing Intelligence \& Planning, 21/4, 249-257. 
Samiee, S. (1999), "The Internationalization of Services: Trends, Obstacles and Issues," Journal of Services Marketing, Vol. 13 No. 4/5. 319-328.

Sangari, E.S., and Foster, T. (1999), "Curriculum Internationalisation A Comparative Study in Iran and Sweden," European Journal of Marketing, Vol. 33 No. 7/8, pp. 760-771.

Sharma, B., and Roy, J.A. (1996), "Aspects of The Internationalization of Management Education," Journal of Management Development, Vol. 15 No. 1. 5-13.

Sherry, J.F. (2000), "Distraction, Destruction, Deliverance: The Presence of Mindscape in Marketings New Millennium," Marketing Intelligence \& Planning, 18,6/7, 328-336.

Sun, H., and Zhang, P. (2004), "An Empirical Study of the Roles of Affective Variables in User Adoption of Search Engines," Proceedings of the Third Annual Workshop on HCl Research in MIS, Washington, D.C., December 10-11.

Svensson, L.G. (1994), "Formation of Professional Values Towards Europe: The Role of Professional Education and Organisation," Higher Education Policy, 7(3), pp. 27-33.

UNESCO, World Conference on Higher Education - Follow-up Strategy, (http://www.unesco.org/education/), didownload 05 Juli 2002.

Wattananimitkul, W., Revisiting The Mission and Educational Strategic Management of Universities, Siam University, Thailand, didownload Maret, 2004

Wedgwood, M. (2004), "Higher Education and The Creative Industry Sector of The Northwest," Manchester Metropolitan University, February 2002, Discussion Paper, didownload Maret.

Welch, A.R. (1997), "The Peripatetic Professor: The Internationalisation of The Academic Profession," Higher Education, 34(3), pp. 323-345.

Welch, A.R., and Denman, B. (1997), "Internationalisation of Higher Education: Retrospect and Prospect," Forum of Education, 52(1), pp. 14-29.

Winsted, K.F. and Patterson, P.G. (1998), "Internationalization of Services: The Service Exporting Decision," The Journal of Services Marketing, Vol. 12 No. 4, 294-311.

Winsted, K.F. (1999), "Evaluating Service Encounters: A Cross-Cultural and Cross-Industry Exploration," Journal of Marketing Theory and Practice, Vol. 7 No. 2, pp. 106-23.

Yang, R. (2002), "University Internationalisation: Its Meanings, Rationales and Implications," Intercultural Education, Vol. 13, No. 1. 82-95. 